\title{
IMAGES OF MULTILINEAR POLYNOMIALS OF DEGREE UP TO FOUR ON UPPER TRIANGULAR MATRICES
}

\author{
Pedro S. Fagundes and Thiago C. DE Mello
}

Abstract. We describe the images of multilinear polynomials of degree up to four on the upper triangular matrix algebra.

Mathematics subject classification (2010): 16S50, 15A54.

Keywords and phrases: Images of polynomials, upper triangular matrices, Lvov-Kaplansky conjecture.

\section{REFERENCES}

[1] A. A. Albert And B. Muckenhoupt, On matrices of trace zero, Michigan Math. J. 4 (1957), 1-3.

[2] S. A. Amitsur And L. Rowen, Elements of reduced trace 0, Israel J. Math. 87 (1994), 161-179.

[3] D. BuZinski AND R. Winstanley, On multilinear polynomials in four variables evaluated on matrices, Linear Algebra Appl. 439 (2013), 2712-2719.

[4] Dniester notebook: unsolved problems in the theory of rings and modules, Non-associative algebra and its applications, Lect. Notes Pure Appl. Math., vol. 246, Chapman \& Hall/CRC, Boca Raton, FL, 2006, pp. 461-516. Translated from the 1993 Russian edition by Murray R. Bremnerand Mikhail V. Kochetov and edited by V. T. Filippov, V. K. Kharchenko and I. P. Shestakov.

[5] G. FALK, Konstanzelemente in Ringen mit Differentiation, Math. Ann. 124 (1952), 182-186.

[6] M. HaLl, A basis for free Lie rings and higher commutators in free groups, Proc. Amer. Math. Soc. 1 (1950), 575-581.

[7] A. Kanel-Belov, S. Malev And L. Rowen, The images of non-commutative polynomials evaluated on $2 \times 2$ matrices, Proc. Amer. Math. Soc. 140 (2012), 465-478.

[8] Z. Mesyan, Polynomials of small degree evaluated on matrices, Linear Multilin. Alg. 61 (2013), 1487-1495.

[9] K. SHodA, Einige Sätze über Matrizen, Jap. J. Math. 13 (1936), 361-365.

[10] Š. ŠPENKO, On the image of a noncommutative polynomial, J. Algebra 377 (2013), 298-311. 